\title{
Determinants of Spatial Dispersion of P-Wave, QRS Complex, and QT-Interval on 12-Lead Electrocardiogram in Apparently Healthy Adults
}

\section{Nelson I Oguanobi ${ }^{1 *}$, Charles U Odenigbo ${ }^{2}$, Ogonna C Oguejiofor ${ }^{2}$, Uchenna C Okonkwo ${ }^{2}$, Ukamaka M Odenigbo ${ }^{3}$ and Tobenna Agogbua ${ }^{1}$}

\author{
${ }^{1}$ Department of Internal Medicine, University of Nigeria Teaching Hospital Enugu, Nigeria \\ ${ }^{2}$ Department of Internal Medicine, Nnamdi Azikiwe University Teaching Hospital Nnewi, Nigeria \\ ${ }^{3}$ Department of Medicine, University of Calabar Teaching Hospital, Nigeria \\ ${ }^{4}$ Department of Dietetics, Federal University of Agriculture Umudike, Nigeria
}

*Corresponding author: Nelson I Oguanobi, Department of Medicine, University of Nigeria Teaching Hospital Enugu, Nigeria

\begin{abstract}
Background: The spatial dispersion of P-wave, QRS complex, and QT interval on 12-lead electrocardiogram are related to the electrical instability in cardiac conducting tissues and elevated parameters are associated with increased risk of cardiovascular morbidity and mortality.

Objectives: We sought to evaluate the dispersion of P-wave, QRS complex, and QT interval in healthy adult Nigerians and assess their relationship to age, gender, anthropometric and some physiologic parameters.

Methods: A total of 128 subjects were recruited for the study. The participants consist of two groups; a young age group of 62 apparently healthy individuals (aged 18-35 years) and an elderly age group of 66 participants (aged 60-89 years) drawn from attendees to the quarterly medical lectures of the Ebreime Foundation for the Elderly, a non-Governmental organization. The exclusion criteria for the study were presence of acute or chronic illnesses and medications capable of affecting electrocardiogram. All subjects had background medical history assessment, clinical examination and resting 12-lead electrocardiography. The dispersion of P-wave, QRS and QT intervals were measured manually under magnifying glass by one observer and were taken as the difference between the maximum and minimum values of each parameter on standard 12lead electrocardiogram.
\end{abstract}

Results: The elderly subjects had significantly higher body mass index compared to the young subjects. Blood pressure indices were comparable in the two groups. The dispersions of P-wave, QRS and QT on 12-lead electrocardiography were all significantly increased in the elderly. Significant gender variations were noted in QRS dispersion, QTc interval and QT dispersion which were all significantly increased in women. A significant correlation was noted between QT dispersion and body mass index $(r=0.280 ; p=0.023)$.

Conclusion: Age, gender and body mass index are significant determinants of P-wave, QRS, and QT dispersion in the adult population. Identification of high risk individuals for cardiovascular disease for prompt preventive intervention is of prime importance.

\section{Keywords}

Determinants, Spatial, Dispersions, Electrocardiogram, Healthy, Adults

\section{Introduction}

Heterogeneity in cardiac depolarization and repolarization on 12-lead electrocardiogram (ECG) has been identified as an important risk factor for lethal cardiac arrhythmias $[1,2]$. The spatial dispersion of P-wave, QRS complex, and QTC interval on 12-lead electrocardiogram are related to the electrical instability in cardiac conducting tissues and elevated parameters are associated with increased risk of cardiovascular morbidity and mortality [1-5]. Elucidation of impacts of various 
clinical variables on ECG dispersions has been subject of research interest largely because of their non-invasive and potentially useful clinical applications.

\section{Objective}

We sought to evaluate the dispersions of P-wave, QRS complex, and QTc interval in healthy adult Nigerian subjects and assess their relationship to age, gender, anthropometric and some physiologic parameters.

\section{Methods}

A total of 128 subjects were recruited for the stu$d y$. The participants consist of two groups; a young age group of 62 persons (aged 18-35) and an elderly group (66 in number aged 60-89). The young volunteers were made of students, hospital workers as well as members of the local community. The elderly participants were drawn from attendees to the quarterly medical lectures of the Ebreime Foundation for the Elderly, a non-Governmental Organization. The exclusion criteria for the study were presence of acute illness or history/documentation of chronic illnesses and medications capable of affecting electrocardiogram such as hypertension, diabetes, significant alcohol intake, use of tobacco, drug abuse. Individuals who were on treatment with drugs capable of affecting ventricular depolarization and repolarization were excluded. The study was conducted in the medical outpatient clinics of Federal Medical Center, Asaba, Delta State, Nigeria. The study was approved by the ethical committees of Federal Medical Center, Asaba, Nigeria Informed consent was obtained from all the participants. All subjects had background medical history assessment with the aid of a questionnaire and then clinically examined to evaluate their cardiovascular status at rest. Resting 12-lead electrocardiography were performed on all subjects using Schiller electrocardiography machine at a paper speed of $25 \mathrm{~mm} / \mathrm{s}$ and standardized at $0.1 \mathrm{mv} / \mathrm{mm}$. A single observer analyzed the electrocardiogram. Measurements of the heart rate, cardiac axis, PR-interval, QRS duration and QTc interval were done in the standard fashion [6]. Heart rate cor- rection of the QT-interval was performed using Bazett's formula (QTC $=$ QT/VRR) [7]. The dispersion of $p$-wave, QRS and QTc intervals were measured manually under magnifying glass by one observer and were taken as the difference between the maximum and minimum values of each parameter on standard 12-lead electrocardiogram $[1,2,5]$. Randomly selected electrocardiograms were cross checked for accuracy and quality control independently by two cardiologists.

\section{Data Analysis}

Descriptive statistics for baseline data were presented as both means and standard deviations for continuous variables or percentages for discrete variables. Differences of the means between groups were compared with the independent Student's T-test.

For discrete variables, distributions between groups were compared with chi-square test and Fishers exact test as appropriate. Multivariate Pearson's correlation coefficient analysis was used to evaluate relationship between ECG dispersions ( $P$ wave, dispersion, QRS and QTc dispersion) and clinical parameters.

All statistical analyses were conducted using the statistical packages for social sciences (SPSS Inc. Chicago Illinois) software version 22.0. Statistical tests at 95\% confidence interval with probability values less than 0.05 were considered statistically significant.

Intra-observer variability of manual ECG measurements was quantified by blinded and randomly sorted repeat measurements of 30 tracings a month after the original measurements were made. There was no statistically significant intra-observer variability.

\section{Results}

The anthropometric and blood pressure indices of the participants are compared in Table 1 and Table 2. The elderly subjects had significantly higher body mass index (BMI) compared to the young subjects. Blood pressure indices were comparable in the two groups.

Table 1: Age, gender and anthropometry.

\begin{tabular}{|l|l|l|l|l|}
\hline Parameters & $\begin{array}{l}\text { Young } \\
\text { Mean (SD) }\end{array}$ & $\begin{array}{l}\text { Elderly } \\
\text { Mean(SD) }\end{array}$ & T-Test & P-Value \\
\hline Age (years) & $28.37(5.91)$ & $68.68(7.92)$ & 32.471 & $<0.0001^{*}$ \\
\hline Gender ffrequency (\%)\} & & & & \\
Male & $31(50)$ & 46 & 4.386 & $0.362^{\text {a }}$ \\
Female & $31(50)$ & 20 & & \\
\hline Total & 62 & 66 & 0.478 & 0.6333 \\
\hline Weight $(\mathrm{kg})$ & $67.35(8.37)$ & $66.50(11.40)$ & 5.369 & $<0.0001^{*}$ \\
\hline Height $(\mathrm{m})$ & $1.72(0.07)$ & $1.62(0.13)$ & 2.234 & $0.0272^{*}$ \\
\hline Body mass index $\left(\mathrm{Kg} / \mathrm{m}^{2}\right)$ & $23.87(3.22)$ & $25.38(4.31)$ & & \\
\hline
\end{tabular}

*: Statistically significant

a: Chi-square 
Table 2: Blood pressure indices in the elderly and young.

\begin{tabular}{|l|l|l|l|l|}
\hline Parameters & $\begin{array}{l}\text { Elderly } \\
\text { Mean (SD) }\end{array}$ & $\begin{array}{l}\text { Young } \\
\text { Mean (SD) }\end{array}$ & T-Test & P-Value \\
\hline Pulse rate (beat/min) & $67.76(13.74)$ & $72.13(6.79)$ & 2.258 & $0.0256^{*}$ \\
\hline Brachial systolic BP $(\mathrm{mmHg})$ & $125.02(17.27)$ & $121.2(8.97)$ & 1.521 & 0.131 \\
\hline Brachial diastolic BP $(\mathrm{mmHg})$ & $78.88(11.07)$ & $76.88(6.18)$ & 1.264 & 0.2087 \\
\hline Brachial pulse pressure $(\mathrm{mmHg})$ & $46.14(12.27)$ & $44.31(10.91)$ & 0.890 & 0.3754 \\
\hline Mean brachial arterial BP $(\mathrm{mmHg})$ & $94.26(12.16)$ & $91.71(5.47)$ & 1.513 & 0.1327 \\
\hline
\end{tabular}

*: Statistically significant

Table 3: Comparison of electrocardiographic characteristics of the elderly and controls.

\begin{tabular}{|l|l|l|l|l|}
\hline \multirow{2}{*}{ Variables } & \multicolumn{2}{|c|}{ Values (Mean SD) } & T- Test & P-Value \\
\cline { 2 - 5 } & Elderly & Young & & $<0.001^{*}$ \\
\hline Heart rate (beat/min) & $67.76(13.74)$ & $68.98(4.24)$ & 6.327 & $<0.0001^{*}$ \\
\hline P-wave duration (msec) & $117.42(14.48)$ & $90.30(14.84)$ & 10.463 & $<0.0001^{*}$ \\
\hline P-wave dispersion (msec) & $58.18(22.94)$ & $34.7(17.41)$ & 6.488 & $<0.0001^{*}$ \\
\hline PR-interval (msec) & $175.53(26.70)$ & $161.3(27.13)$ & 2.990 & 0.3484 \\
\hline QRS duration (msec) & $84.08(15.19)$ & $81.5(15.82)$ & 0.941 & $<0.0001^{*}$ \\
\hline QRS dispersion (msec) & $45.45(18.02)$ & $33.3(14.57)$ & 4.325 & $<0.0002^{*}$ \\
\hline QTc-interval (msec) & $411.91(31.13)$ & $393.5(21.46)$ & 3.872 & $<0.0001^{*}$ \\
\hline QTc-dispersion & $66.64(11.61)$ & $47.8(21.23)$ & 6.280 & $<$ \\
\hline
\end{tabular}

*: Statistically significant

Table 4: Gender variation in ECG parameters.

\begin{tabular}{|l|l|l|l|l|}
\hline \multirow{2}{*}{ Variables } & \multicolumn{2}{|c|}{ Values (Mean SD) } & T- Test & P-Value \\
\cline { 2 - 5 } & Male & Female & & 0.463 \\
\hline Heart rate (beat/min) & $67.07(15.27)$ & $69.35(9.48)$ & 0.739 & 0.862 \\
\hline P-wave duration (msec) & $117.22(15.26)$ & $117.90(12.86)$ & 0.175 & 0.978 \\
\hline P-wave dispersion (msec) & $58.13(3.74)$ & $58.30(4.96)$ & 0.027 & 0.561 \\
\hline PR-interval (msec) & $176.80(29.91)$ & $172.60(17.51)$ & 0.585 & $0.0061^{*}$ \\
\hline QRS duration (msec) & $86.43(10.77)$ & $78.65(8.88)$ & 2.835 & $0.0067^{*}$ \\
\hline QRS dispersion (msec) & $44.78(2.73)$ & $47.00(3.42)$ & 2.802 & 0.836 \\
\hline QT-interval (msec) & $391.41(44.65)$ & $389.20(23.93)$ & .208 & $0.0099^{*}$ \\
\hline QTc-interval (msec) & $408.65(15.18)$ & $419.40(14.81)$ & 2.680 & $<0.0001^{*}$ \\
\hline QTc- dispersion & $52.57(2.95)$ & $63.00(5.85)$ & 9.652 & \\
\hline
\end{tabular}

*: Statistically significant

However, the younger participants had higher pulse rate (Table 2). The dispersions of P-wave, QRS and QT on 12-lead electrocardiography were all significantly increased in the elderly, (Table 3). Significant gender variations were noted in QRS dispersion, QTc and QT dispersion measurement which were all significantly increased in women than men (Table 4). A significant correlation was noted between QT dispersion and BMI $(r=280 ; p=0.023)$.

The distributions of minimum and maximum P-waves, QRS and QT in 12-lead electrocardiogram in the elderly are shown in Table 5.

Maximum values of P-wave were mainly located in Lead II (63.64\%), while minimum values were mainly found in the right precordial Leads V1 and V2 in $37.28 \%$ and $19.79 \%$ of the participants respectively. For QRS duration, maximum values occurred in the frontal Leads 1, II, III, while minimum parameters occurred in Leads I (19.715) and AVR (36.36\%). Maximum QT were mainly located in Leads I, II, III and V2, while minimum values were observed in leads I (22.73\%) and V1 (16.67\%).

\section{Discussion}

Increased dispersion of durations of the P wave, QRS complex, and QT-interval has been associated with the risk of atrial fibrillation, ventricular arrhythmias, sudden cardiac death, as well as with a general negative prognosis in various settings [1-4].

Our study revealed increase in these non-invasive 
Table 5: The distributions of minimum and maximum P-waves, QRS and QT in 12-lead electrocardiogram in the elderly.

\begin{tabular}{|c|c|c|c|c|c|c|}
\hline \multirow{2}{*}{ Lead } & \multicolumn{6}{|c|}{ Frequency (\%) } \\
\hline & P-Wave Max & P-Wave Min & QRS Max & QRS Min & QT Max & QT Min \\
\hline V1 & $0(0)$ & $25(37.88)$ & $4(6.06)$ & $3(4.55)$ & $1(1.52)$ & $15(22.73)$ \\
\hline V2 & $0(0)$ & $13(19.70)$ & $9(13.64)$ & $1(1.52)$ & $8(12.12)$ & $3(4.55)$ \\
\hline V3 & $0(0)$ & $2(3.03)$ & $6(9.09)$ & $0(0)$ & $3(4.55)$ & $0(0)$ \\
\hline V4 & $1(1.52)$ & $0(0)$ & $1(1.52)$ & $2(3.03)$ & $3(4.55)$ & $4(6.06)$ \\
\hline V5 & $0(0)$ & $2(3.02)$ & $2(3.03)$ & $2(3.03)$ & $4(6.06)$ & $3(4.55)$ \\
\hline V6 & $2(3.03)$ & $1(1.52)$ & $3(4.55)$ & $4(6.06)$ & $5(7.58)$ & $1(1.52)$ \\
\hline I & $0(0)$ & $8(12.12)$ & $3(4.55)$ & $13(19.70)$ & $9(12.64)$ & $11(16.67)$ \\
\hline II & $42(63.64)$ & $0(0)$ & $7(10.61)$ & $2(3.03)$ & $12(18.18)$ & $4(6.06)$ \\
\hline III & $1(1.52)$ & $2(3.03)$ & $11(16.67)$ & $2(3.03)$ & $11(16.67)$ & $3(4.55)$ \\
\hline aVF & $4(6.06)$ & $3(4.55)$ & $5(7.58)$ & $1(1.52)$ & $6(9.09)$ & $3(4.55)$ \\
\hline aVR & $7(10.61)$ & $1(1.52)$ & $1(1.52)$ & $24(36.36)$ & $3(4.55)$ & $5(7.58)$ \\
\hline $\mathrm{aVL}$ & $0(0)$ & $0(0)$ & $5(7.58)$ & $3(4.55)$ & $1(1.52)$ & $4(6.06)$ \\
\hline
\end{tabular}

electrocardiographic markers in the elderly subjects. Similar impact of aging on these parameters has been reported $[8,9]$.

The increased P-wave dispersion in the elderly may be related to the dilatation of the atria and associated altered cardiac pre-load and after-load characteristics predisposing to atrial fibrillation $[10,11]$. The value of increased $\mathrm{P}$-wave duration and $\mathrm{P}$-wave dispersion as independent predictors of atrial arrhythmias has been confirmed in several studies $[10,11]$. The mean value for $\mathrm{P}$-wave dispersion (PWD) in the elderly participants in our study is $58.18 \pm 22.94$ milliseconds. This is significantly higher than the normal value of PWD of $29 \pm 9 \mathrm{~ms}$ $[10,11]$. PWD values $\geq 40$ ms has been shown to indicate the presence of heterogeneous electrical activity in different regions of the atrium that might cause atrial tachyarrhythmias [10].

The mean QRS dispersion (QRSd) in our elderly participants was $44.78 \pm 2.73$ and $47.00 \pm 13.42$ milliseconds in males and females respectively. A cut-off value of 46 milliseconds for QRSd has been used to identify chronic heart failure patients with high risk of death in three years $[2,12]$.

In studies of patient with chronic heart failure, myocardial infarction and arrhythmogenic cardiomyopathy, the cut-off value of 40 milliseconds for QRSd separated the patients in two groups with significant structural differences on cardiac imaging $[13,14]$.

Increased QT-dispersion was noted in our elderly subjects with mean QT dispersion of $52.57 \pm 2.95$ and $63.00 \pm 5.85$ milliseconds in males and females respectively. Literature reviews found the QT dispersion to vary mostly between 30 and $60 \mathrm{~ms}$ in normal subjects $[15,16]$. Age-related differences were reported to be statistically significant in some studies $[17,18]$.

Previous studies showed that women have longer QT dispersion values than men $[19,20]$. This gender-re- lated difference is probably due to sex hormone mediated prolongation of the duration of ventricular repolarisation in women and is manifests only after puberty [21-23].

Several large prospective studies have assessed the predictive value of QT dispersion for cardiac and all-cause mortality in the general population. Data from these studies have consistently validated the significant independent prognostic value of QT-dispersion in a wide range of clinical settings $[24,25]$. Body mass index is the only anthropometric variable found to determine the variability of cardiac repolarization and depolarization. Our observation is similar to those of Mangoni AA, et al. [9] and Hanci V, et al. [26] who independently reported significant correlation between QT dispersion and body mass index. This relationship may be due to increase in cardiac output in subjects with higher body mass index and subsequent development of subclinical cardiac hypertrophy [27].

Classification and quantification of the regional information on ECG dispersion indices in the 12-lead ECG remains a challenge. This study observed maximum values for P-wave, QRS, QT in the frontal leads I, II, and III in the elderly. It is difficult to explain the significance and implications of this finding. Previous studies have demonstrated that the duration and dispersion of the QRS were higher in the ECG leads showing acute ischaemias, suggesting that that the odds of ventricular arrhythmias during the occurrence of an acute myocardial infarction are much higher when the duration and dispersion of the QRS are higher $[28,29]$.

Kors, et al. [30] found that QT dispersion was significantly different between patients with narrow $(54.2 \pm$ $27.1 \mathrm{~ms})$ and wide T loops $(69.5 \pm 33.5 \mathrm{~ms}, \mathrm{p}<0.001)$. They also showed that in each of the six limbs as well as the six precordial leads, the difference between the QT interval in a lead and the maximum QT interval was dependent on the angle between the axis of the lead 
and the axis of the terminal part of the T loop. Regions of shortest QT intervals always coincided with the location of the isoelectric zero potential line [31]. These studies have shown that the interlead differences of the QT intervals are a reflection of the morphology of the T wave loop.

\section{Conclusion}

Age, gender and body mass index are significant determinants of P-wave, QRS, and QTc dispersion in the adult population. Identification of high risk individuals for cardiovascular disease for prompt preventive intervention is of prime importance.

\section{Conflict of Interest}

The authors have no potential conflict of interests.

\section{Declarations of Interest}

None.

\section{References}

1. Dilaveris PE, Gialafos JE (2001) P-wave dispersion: A novel predictor of paroxysmal atrial fibrillation. Ann Noninvasive Electrocardiol 6: 159-165.

2. Anastasiou-Nana MI, Nanas JN, Karagounis LA, Tsagalou EP, Alexopoulos GE, et al. (2000) Relation of dispersion of QRS and QT in patients with advanced congestive heart failure to cardiac and sudden death mortality. Am J Cardiol 85: $1212-1217$.

3. Glacy JM, Garratt CJ, Woods KL, de Bono DP (1995) QT dispersion and mortality after myocardial infarction. Lancet 345: 945-948.

4. Day CP, Mc comb JM, Campbell RW (1990) QT dispersion: An indication of arrhythmia risk in patients with long QT intervals. Br Heart J 63: 342-344.

5. Puddu PE, Bourassa MG (1986) Prediction of sudden death from QTc interval prolongation in patients with chronic ischemic heart disease. J Electrocardiol 19: 203-211.

6. Mirvis DM, Goldberger AL (2005) Electrocardiography. In: Zipes D, Libby P, Bonow R, Braunwald E, Braunwald's heart disease: A textbook of cardiovascular medicine. $\left(7^{\text {th }}\right.$ edn), WB Saunders Co., Philadelphia, PA, 107-152.

7. Bazett HC (1920) An analysis of the time-relations of electrocardiograms. Heart 7: 353-370.

8. Huang JH, Lin YQ, Pan NH, Chen YJ (2010) Aging modulates dispersion of ventricular repolarization in the very old of the geriatric population. Heart Vessels 25: 500-508.

9. Mangoni AA, Kinirons MT, Swift CG, Jackson SHD (2003) Impact of age on QT interval and QT dispersion in healthy subjects: A regression analysis. Age Ageing 32: 326-331.

10. Aytemir K, Ozer N, Atalar E, Sade E, Aksoyek S, et al. (2000) P wave dispersion on 12-lead electrocardiography in patients with paroxysmal atrial fibrillation. Pacing Clin Electrophysiol 23: 1109-1112.

11. Perez-Riera AR, De Abreu LC, Barbosa-Barros R, Grindler J, Fernandes-Cardoso A, et al. (2016) P-wave dispersion: An update. Indian Pacing Electrophysiol J 16: 126-133.

12. Sakata $K$, Shimizu M, Ino $H$, Yamaguchi $M$, Terai $H$, et al (2003) QT dispersion and left ventricular morphology in patients with hypertrophic cardiomyopathy. Heart 89: 882-886.
13. Ma N, Cheng H, Lu M, Jiang S, Yin G, et al. (2012) Cardiac magnetic resonance imaging in arrhythmogenic right ventricular cardiomyopathy: Correlation to the QRS dispersion. Magn Reson Imaging 30: 1454-1460.

14. Donoiu I, Târtea GC, Chávez-González E (2017) Is there a utility for QRS dispersion in clinical practice? J Mind Med Sci 4: 132-141.

15. Kautzner J, Malik M (1997) QT interval dispersion and its clinical utility. Pacing Clin Electrophysiol 20: 2625-2640.

16. Statters DJ, Malik M, Ward DE, Camm AJ (1994) QT dispersion: Problems of methodology and clinical significance. J Cardiovasc Electrophysiol 5: 672-685.

17. Savelieva I, Camm AJ, Malik M (1993) QT dispersion should be adjusted for age: Observations from 1096 normal subjects. J Am Coll Cardiol 33: 129A.

18. Zhang N, Ho TF, Yip WCL (1999) QT dispersion in healthy Chinese children and adolescents. Ann Noninvas Electrocardiol 4: 281-285.

19. Molnar J, Zhang F, Weiss J, Ehlert FA, Rosenthal JE (1996) Diurnal pattern of QTc interval: How long is prolonged? Possible relation to circadian triggers of cardiovascular events. J Am Coll Cardiol 27: 76-83.

20. Sagie A, Larson MG, Goldberg RJ, Bengston JR, Levy D (1992) An improved method for adjusting the QT interval for heart rate (the Framingham Heart Study). Am J Cardiol 70: $797-801$

21. Merri M, Benhorin J, Alberti M, Locati E, Moss AJ (1989) Electrocardiographic quantitation of ventricular repolarization. Circulation 80: 1301-1308.

22. Stramba-Badiale M, Spagnolo D, Bosi G, Schwartz PJ (1995) Are gender differences in QTc present at birth? MISNES Investigators. Multicenter Italian study on neonatal electrocardiography and sudden Infant death syndrome. Am J Cardiol 75: 1277-1278.

23. Rautaharju PM, Zhou SH, Wong S, Calhoun HP, Berenson GS, et al. (1992) Sex differences in the evolution of the electrocardiographic QT interval with age. Can J Cardiol 8: 690-695.

24. de Bruyne MC, Hoes AW, Kors JA, Hofman A, van Bemmel $\mathrm{JH}$, et al. (1998) QTc dispersion predicts cardiac mortality in the elderly. The Rotterdam study. Circulation 97: 467472.

25. Okin PM, Devereux RB, Howard BV, Fabsitz RR, Lee ET, et al. (2000) Assessment of QT interval and QT dispersion for prediction of all-cause and cardiovascular mortality in American Indians. The Strong Heart Study. Circulation 101: 61-66.

26. Hanci V, Ayoğlu H, Yurtlu S, Yildirim N, Okyay RD, et al. (2010) An evaluation of P wave dispersion, QT, corrected QT and corrected QT dispersion intervals on the electrocardiograms of malnourished adults. Anaesth Intensive Care 38: $122-127$.

27. De Simone G, Devereux RB, Daniels SR, Mureddu G, Roman MJ, et al. (1997) Stroke volume and cardiac output in normotensive children and adults. Assessment of relations with body size and impact of overweight. Circulation 95: 1837-1843.

28. Chávez-González E, Rodríguez Jiménez AE, Moreno-Martínez FL (2017) QRS duration and dispersion for predicting ventricular arrhythmias in early stage of acute myocardial infraction. Med Intensiva 41: 347-355.

29. Hetland M, Haugaa KH, Sarvari SI, Erikssen G, Kongsga- 
ard E, et al. (2014) A novel ECG-index for prediction of ventricular arrhythmias in patients after myocardial infarction. Ann Noninvasive Electrocardiol 19: 330-337.

30. Kors JA, van Herpen G, van Bemmel JH (1999) QT dispersion as an attribute of T-loop morphology. Circulation 99: 1458-1463.
31. Punske BB, Lux RL, MacLeod RS, Fuller MS, Ershler PR, et al. (1999) Mechanisms of the spatial distribution of QT intervals on the epicardial and body surfaces. J Cardiovasc Electrophysiol 10: 1605-1618. 